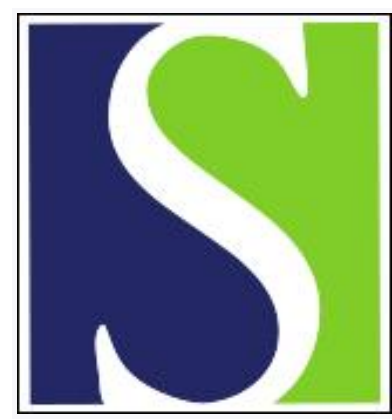

Scand J Work Environ Health 2011;37(6):481-493

https://doi.org/10.5271/sjweh.3173

Published online: 10 Jun 2011, Issue date: Nov 2011

What promotes sustained return to work of employees on long-term sick leave? Perspectives of vocational rehabilitation professionals

by Dekkers-Sánchez PM, Wind H, Sluiter JK, Frings-Dresen MHW

Affiliation: Academic Medical Center, Coronel Institute of Occupational Health/Research Center for Insurance Medicine, PO Box 22700, NL-1100 DE Amsterdam, The Netherlands. p.m.dekkers@amc.uva.nl

Refers to the following texts of the Journal: 2005;31(5):367-374 2010;36(6):473-483

The following article refers to this text: 2012;38(2):89-91

Key terms: long-term sick leave; long-term sickness absence; return to work; return-to-work facilitators; RTW; RTW coordinators; sick leave; sickness absence; sickness absence; vocational rehabilitation; work disablement; work rehabilitation

This article in PubMed: www.ncbi.nlm.nih.gov/pubmed/21667007 


\title{
What promotes sustained return to work of employees on long-term sick leave? Perspectives of vocational rehabilitation professionals
}

\author{
by Patricia M Dekkers-Sánchez, MD, MSc, 1, 2 Haije Wind, MD, PhD,1, 2 Judith K Sluiter, PhD, 1, 3 \\ Monique HW Frings-Dresen, PhD 1, 2,3
}

\begin{abstract}
Dekkers-Sánchez PM, Wind H, Sluiter JK, Frings-Dresen MHW. What promotes sustained return to work of employees on long-term sick leave? Perspectives of vocational rehabilitation professionals. Scand J Work Environ Health. 2011;37(6):481-493. doi:10.5271/sjweh.3173
\end{abstract}

Objectives The aim of this study was to (i) explore promoting factors for sustained return to work (RTW), according to vocational rehabilitation professionals (VRP) that are amenable to change for employees who have been on sick leave $>18$ months and (ii) gain insight into crucial aspects of interventions.

Methods Semi-structured interviews were carried out with 23 VRP. All interviews were transcribed fully verbatim. An inductive analysis of the transcripts was performed, using a process of identifying, coding, and categorizing the primary patterns in the data.

Results Key influenceable promoting factors for sustained RTW by long-term sick-listed employees include: employee-based vocational guidance; integral, effective communication between the sick-listed employee and all RTW stakeholders; personal factors; a supportive work environment; and a stimulating social environment. Crucial aspects of interventions include: gathering information and setting priorities; improving qualifications; influencing cognitions; monitoring the sick-listed employee through the rehabilitation process; offering tailormade interventions at different stages within a personal time-bound action plan; and preparing the employee and the work environment for RTW.

Conclusions Sustained RTW for long-term sick-listed employees can be achieved by focusing on the influenceable promoting factors for RTW. The use of combined interventions in a holistic approach involving the worker and his environment is considered the best way to address the multicausality of work disability and could help maximize RTW outcomes.

Key terms long-term sickness absence; return-to-work facilitators; RTW; RTW coordinators; sickness absence; work disablement; work rehabilitation.

Long-term sick leave is a major socioeconomic problem in Western countries due to the enormous financial costs for society (1). Several studies have shown the importance of the return-to-work (RTW) transition process for employees on long-term sick leave (2-4). Early research has shown that the probability of RTW decreases as the duration of sick leave lengthens (5). Achieving early job reintegration of chronic work-disabled employees is a difficult goal to accomplish due to the complexity of factors involved, and the issue needs ongoing attention.

An employee on long-term sick leave is an individual who functions in a complex context in which different factors can play a role, such as medical, personal, envi- ronmental, or work-related factors (6). These factors can either perpetuate sick leave or promote RTW (7) among employees who have been sick-listed for $>1.5$ years; the factors that stimulate RTW may be different from those that facilitate a sustained RTW. Some promoting factors for RTW are potentially influenceable and could offer opportunities for health professionals to improve work participation. Therefore, stimulation of these positive factors is important to facilitate work resumption of employees on long-term sick leave.

There are several important actors involved in the RTW process of a long-term sick-listed employee, such as the sick-listed employee him- or herself and the

\footnotetext{
1 Academic Medical Center, University of Amsterdam, Department: Coronel Institute of Occupational Health. Amsterdam, the Netherlands.

2 Research Center for Insurance Medicine, Academic Medical Center, University of Amsterdam, Amsterdam, the Netherlands.

3 Co-principal investigators in this study.
}

Correspondence to: Patricia Dekkers-Sánchez, Academic Medical Center, Coronel Institute of Occupational Health/Research Center for Insurance Medicine, PO Box 22700, NL-1100 DE Amsterdam, The Netherlands. [E-mail: p.m.dekkers@amc.uva.nl] 
employee's family, employer, vocational rehabilitation professional (VRP), and other health professionals (eg, medical specialists, general practitioners, occupational physicians, insurance physicians). Professionals working in specialized reintegration services are, in comparison with other professionals, the most closely involved in the work rehabilitation process of long-term sick-listed employees. Early studies suggest that the effectiveness of RTW programs may be increased by including specially trained professionals to facilitate the job placement process (3). The titles of these professionals vary per country and include work rehabilitation counselors, RTW coordinators, disability prevention specialists, VRP, and case managers. For consistency sake, in this paper we refer to all these professionals as VRP. Many western countries make use of RTW interventions that include RTW coordinators, which seems to be an effective strategy for preventing workplace disability (8). VRP are thus an important source of information about factors associated with the successful RTW of employees on long-term sick leave.

In the Netherlands, VRP work at specialized vocational rehabilitation services, which are for-profit or non-profit organizations. According to the Dutch legislation, the employee and the employer are responsible for the work reintegration of sick-listed employees during the first two years of sick leave. VRP provide support to the employer in the management of RTW in case of sickness absence. Employers are free to choose the vocational rehabilitation service that best fits the specific needs of their employees. The services offer different work rehabilitation programs according to the specific needs of the sick-listed employee, including a VRP that coordinates the RTW activities such as workplace assessment, worker training, case management, outplacement, career counseling, referral to specific training and training in job applications.

We selected VRP to acquire information pertaining to factors that stimulate RTW because of the important roles these professionals play in the RTW process for the long-term work-disabled. The aim of this study was to explore promoting factors for sustained RTW of employees on sick leave from the perspective of experienced VRP specialized in the reintegration of long-term sick-listed employees. An additional aim was to gain insight into crucial aspects of interventions.

\section{Methods}

For this qualitative study, semi-structured interviews using open-ended questions were conducted face-to-face with VRP working in the Netherlands.

\section{Participants}

The participants were selected by purposive sampling (9) to maximize variability of perspectives and obtain information from a large range of VRP involved in the RTW process. The participants were selected from a directory of professional VRP of the Dutch Association of Work Rehabilitation Counseling. Selection criterion for the VRP consisted of having extensive placement experience with chronic work-disabled employees who had been on sick leave for $\geq 1.5$ years.

\section{Data collection}

Data were collected between July-August 2009 through semi-structured, individual, face-to-face interviews using a topic guide. Twenty interviews were initially planned, and the inclusion of new respondents continued until data saturation was achieved. The participants were contacted via telephone by the interviewer and received additional written information about the research. Consent to participate was obtained from every participant prior to the interviews. Before the interviews started, the purpose of the study was clearly explained and the participants were asked to complete a demographic questionnaire. The demographic questionnaire elicited participants' gender, age, years of work experience, highest academic degree achieved, work setting, type of clients, and field of work. All participants agreed to the audio taping, with the assurance of confidentiality. The audiotapes were transcribed fully verbatim, and the interviewer listened to each interview twice and compared the audio records to the transcripts to ensure their accuracy. Shortly after the interviews took place, participants had the opportunity to check the correctness of the transcripts and provide additional comments via email. The VRP who agreed to participate acknowledged the need for and importance of the stated research objective.

\section{Interview content}

The VRP were asked the following main questions: (i) "According to your experience, what are the influenceable promoting factors for sustained ( $>6$ months) RTW by long-term sick-listed employees?" (ii) "According to your experience, which aspects of your interventions are crucial to achieve sustained RTW of long-term sicklisted employees?"

\section{Interview procedure}

The interviews were conducted by a female insurance physician with extensive knowledge of reintegration of sick-listed employees and significant interviewing experience. The interviewer used techniques of paraphrasing, 
summarization, and clarification to gain a fuller understanding of the points made during the interviews. All interviews were audiotaped in the work settings of the VRP. Individual interviews lasted an average of 60 minutes. We developed a semi-structured, open-ended interview guide to elicit the experts' opinions on the research topics, while allowing exploration of issues that arose and free expression of views.

\section{Sample}

The sample size was directed by data saturation (9), which refers to the point at which no new information is being generated or collected. We believed we had achieved data saturation prior to concluding the $20^{\text {th }}$ interview but decided to conduct a few additional interviews to make sure that saturation had been achieved.

\section{Data analysis}

We performed an inductive analysis of the transcripts, which is a process of identifying, coding, and categorizing the primary patterns in the data. The outcome of this type of data analysis is a set of categories developed into a framework that summarizes the raw data and elucidates key themes (10). All transcripts were electronically coded using the software MAXQDA (VERBI GmbH, Marburg, Germany).

During the content analysis, the data was carefully read several times. Themes and patterns were identified in the data and labeled in a process of open coding. The open coding included a close examination of the data, in a process of breaking down the data into categories. At the same time, similarities and differences between the categories were compared while asking critical questions about the inclusion of the data in the categories. The primary patterns and concepts that emerged from the data were categorized using a systematic, inductive identification of themes and patterns (10).

Initially, two interviews were independently coded by hand by a second author to ensure the inter-rater reliability of the coding. The two authors discussed the codes and reached a consensus regarding the codes. The initial coding frame consisted of 29 codes. As there was substantial agreement between both coders, one author completed the electronic coding of the remaining 21 interviews in MAXQDA. As extra confirmation of inter-coder reliability, two additional interviews were independently coded manually by a separate coder. The program MAXQDA was a useful tool to manage the data. The data were further analyzed following established steps developed for the analysis of qualitative data (9). Codes were compared, contrasted, refined, and grouped into higher-order themes. The data were assessed to discover obvious patterns through a process of axial coding and selective coding. Relations between themes were established and categories were organized into clusters based on similarities of meaning. Main categories, sub-categories and themes were identified. Sub-themes were identified, classified, and linked to the corresponding themes according to their content. The links between RTW interventions and influenceable promoting factors for RTW were established.

The four authors reviewed all stages of coding, discussed the procedure collectively and reached a consensus regarding the final coding, categories and key themes. Special attention was given to the accuracy and relevance of the coding scheme and the emerging themes.

\section{Results}

In total, 40 VRP working in different branches were approached to participate in the study, and 23 VRP consented to be interviewed. Reasons for not participating were mainly lack of time or interest. The participants varied in gender, age, educational level, and professional and cultural backgrounds. Their ages ranged from 32-58 years of age. Their experience in work rehabilitation of sick-listed employees varied between $8-34$ years. Of the 23, 12 VRP were women. The participants worked at 23 work rehabilitation agencies of small, medium, and large sizes, with a number of employees ranging from 4-200 located in 17 cities in different geographical regions of the Netherlands.

Five main themes related to important influenceable promoting factors for sustained return to work emerged from our data.

The most important factors for sustained return to work among long-term sick-listed employees according to the VRP interviewed were: (i) employee-based vocational guidance regarding all aspects of work rehabilitation; (ii) integral and effective communication and collaboration with the sick-listed employee and other RTW stakeholders; (iii) the sick-listed employee as a promoting factor; (iv) a supportive work environment; and (v) a stimulating social environment. Main themes include sub-themes that represent the different points that emerged. Table 1 summarizes the main themes and subthemes. Each theme is illustrated with citations from the interviews, identified by the age, gender, and specialization of the VRP.

\section{Theme 1 - Employee-based vocational guidance}

VRP commented at length about the importance of optimal guidance of long-term sick-listed employees and emphasized that a thorough understanding of all aspects related to the absence of the employee is the starting point for successful work rehabilitation. 
Table 1. Influenceable promoting factors - main themes and subthemes from data. [RTW=return to work.]

\begin{tabular}{ll}
\hline Main themes & Subthemes \\
\hline $\begin{array}{l}\text { 1. Employee-based vocational } \\
\text { guidance }\end{array}$ & $\begin{array}{l}\text { Matching the guidance to the } \\
\text { individual needs of the sick- } \\
\text { listed employee } \\
\text { Providing individual guidance }\end{array}$ \\
$\begin{array}{ll}\text { 2. Integral and effective } \\
\text { communication between the } \\
\text { sick-listed employee and }\end{array}$ & $\begin{array}{l}\text { The benefits of open } \\
\text { all RTW-stakeholders }\end{array}$ \\
& $\begin{array}{l}\text { Interdisciplinary cooperation } \\
\text { between all RTW-stakeholders }\end{array}$ \\
& Communication at same level \\
3. The sick-listed employee as & $\begin{array}{l}\text { Positive personal } \\
\text { promoting factor }\end{array}$ \\
characteristics \\
The importance of work \\
motivation \\
Accepting handicaps and \\
searching new possibilities \\
The meaning of work \\
Characteristics of the workplace \\
Healthy working relationships \\
Adequate physical work \\
environment \\
Stimulating financial measures \\
to improve work participation \\
Having a good social network \\
Tackling social problems \\
\\
\end{tabular}

Matching the guidance to the individual needs of the sick-listed employee. VRP stressed the importance to regard each client as a unique individual with specific problems and needs and not just as a client or work absentee. According to the VRP, a good match between employee-employer and the type of work is decisive for successful work rehabilitation.

A 48-year old female VRP helping blue-collar sicklisted employees return to work for $>25$ years expressed the importance of individual employee attention: "Sicklisted employees should get enough attention and support from employers, colleagues and VRP during the return-to-work process; sick-listed employees should not be left to their own fate, otherwise the reintegration will lead to nothing. They need expert guidance; they have to do something that interests them, something that grabs their attention. But the most important thing is that they are able to perform the work they are supposed to do."

The importance of gathering complete information about the sick-listed employee. VRP found that the more information they gathered about the client, the better they were equipped to tackle the obstacles for RTW of their clients. The participants expressed that information gathering about the client should be as complete as possible because it provides crucial information and helps to choose an adequate intervention and workplace.
A 58-year-old VRP with 32 years experience in the rehabilitation of sick-listed employees working in the maritime sector said: "Spending enough time to explore the personal situation of the sick-listed employee, including his medical, work and social situations facilitates the rehabilitation process. Identifying the real barriers to and facilitators of RTW make it possible to determine priorities and the actions that need to be taken to achieve successful reintegration."

Theme 2 - Integral and effective communication between the sick-listed employee and RTW stakeholders

According to our participants, the communication with sick-listed employees should be open, direct and clear, and the distance between VRP and employee should be as close as possible. This implies that the VRP should communicate on the same level as the employee. The participants stated that an open, honest communication is one of the best ways to build a successful relationship between the VRP and the client. It is important to communicate honestly about the expectations of the client. If the VRP thinks that the client has little chance to succeed, then he should be open about this. Clients who are actively encouraged to share their ideas feel more valued and have more confidence in the VRP, which improves the work reintegration process. According to VRP, hierarchical relationships with the client should be avoided because it interferes with the communication. Clients feel freer to talk to a VRP if he or she has their own communication style. This lack of social barriers within the client-VRP relationship and the ability to speak the same language enhances the communication and the reintegration process as well as the relationship with the client and, as a result of this, improves work reintegration. The sub-themes identified were related to the benefits of open communication, interdisciplinary cooperation between all RTW stakeholders, and the relevance of communication at the same level.

The benefits of open communication. Taking the problems of clients seriously, treating them respectfully and showing empathy were mentioned as important promoting factors for RTW. Besides providing support to the sick-listed employees, some VRP found that it is also necessary to promote self-responsibility and self-care. Providing a realistic understanding of the medical condition, expected recovery and implications for the work situation are important promoting factors.

The following excerpt of a 38-year old female VRP working for 15 years with low-educated sick-listed employees illustrates the importance of open communication: "Good communication includes an honest, open approach, speaking at the same level as the client and being clear about the possibilities and impossibilities in 
the reintegration; but this also means that there is a need to take the client seriously and to treat him respectfully. It is very important to set clear rules and explain the consequences of the choices made. This form of communication promotes client confidence in the VRP and increases the employee's chance of returning to work."

\section{Interdisciplinary cooperation between RTW stakeholders.}

VRP stressed the importance of multidisciplinary teams who collaborate with each other, because long-term sicklisted employees often have diffuse or multiple problems that need different specialists. This differentiation is required to provide tailor-made guidance according to the specific type of employee, his or her education level, and the nature of the complaint. All stakeholders involved in the RTW of the sick-listed employee should work in the same direction and communicate effectively. It is important that healthcare professionals incorporate RTW goals and timelines into their medical advice. Professionals should work towards common agreed goals between the sick-listed employee, healthcare providers, supervisors, management and social security officers.

A 38-female VRP with 8 years experience in the private sector explained: "There is no ready plan of action for a specific type of employee. Employees should get specialized guidance according to their own problems and specific needs. Sick-listed employees often have different types of problems and all of these problems should be treated by the right person. It is necessary that all persons involved in the rehabilitation process, including clients, healthcare professionals, supervisors and work rehabilitation professionals work in the same direction and collaborate with each other; this means that they should have a common goal: to achieve early and durable return to work of the sick-listed employee."

Communication at the same level. In the case of employees speaking another language, it is crucial that the VRP speak the same language and be aware of the cultural background of the employee to be able to understand the views of the employee. In some specific cases, the VRP advised a home visit to the employee to obtain an impression of the private situation and to get to know the family of the employee and involve family members in the rehabilitation process. This improves the communication and the confidence of the client, especially for workers who experience intimidating obstacles in their RTW.

A 50-year old female VRP specialized in the reintegration of long-term sick-listed blue-collar foreign workers with great difficulties acquiring jobs put it this way: "These sick-listed employees not only have medical problems but they often have serious psychosocial and financial problems related to their backgrounds and difficult social situations. The VRP should enter into the world of the employee and gain her/his confidence. This is only possible if you speak the same language and are able to understand the views and moral standards from the perspective of the sick-listed employees."

\section{Theme 3 - the long-term sick-listed employee as promoting factor}

VRP considered sick-listed employees as active partners and resources for their own rehabilitation. The respondents indicated that positive individual characteristics of the sick-listed employee, such as work motivation, positive expectations about recovery, high levels of self-efficacy, strong work ethic, flexibility, degree of acceptance of one's own sickness, healthy self-esteem, and self-confidence, are promoting factors for RTW.

A 56-year old female VRP helping sick-listed employees return to work for $>25$ years, explained how the employee can act as a promoting factor: "There are many potentially modifiable factors that can promote return to work. In my opinion, one of the most important factors is the sick-listed employee himself. You can use expensive and sophisticated methods to help people reintegrate to work, but if the employee is not willing to collaborate and to work hard towards his own work resumption, it will be almost impossible to succeed. One of the most crucial things is to first identify the barriers you are dealing with. If the barriers to reintegration are located in the employee (such as beliefs, feelings, customs, behavior), then you should first try to overcome these obstacles. The VRP should be well informed about the personal and work situation of his client and apply special techniques according to the specific needs and personality of the client. Some sick-listed employees are not aware of the fact that their own ideas, behavior and fears are the main obstacles that impede them to get a better life. My task is to open the eyes of my clients, make them realize that they have choices, and to make them see that they have the potential to change their own lives and improve their own future and the future of their children. Sometimes it is a difficult task, but it is very rewarding to see people change in the right direction."

Work motivation is half the work. Our participants agreed that work motivation and having a positive attitude towards work are some of the most important factors in returning to work. Motivated sick-listed employees have proactive attitudes and explore by themselves the possibilities of returning to work and work towards their goals of work resumption.

A 48-year old female VRP with 17 years experience with sick-listed bank employees noted: "Motivation is undoubtedly a crucial factor. It truly makes a difference if the sick-listed employee is self-motivated to return to work or if he is motivated by his family, peers or 
colleagues. It is indispensable that a person has a healthy work ethic and that he really wants to work. A motivated employee is half the work, and then you should motivate the employer to give him a chance despite his sickness and his older age."

Accepting handicaps, searching for new possibilities. Most of our participants stressed the importance of employee acceptance of the new situation after disease or injury before starting a new job. Long-term sick-listed employees need first to accept their own handicaps and disabilities to be able to function in a new work environment.

An experienced 52-year-old female VRP who has been working for 22 years with long-term sick-listed teachers and office workers stressed the importance of flexibility and the acceptance of a client's own disabilities: "The first thing to do is to make it clear to the sicklisted employee that there is no way back and that there is only a way forward and that is the reintegration path. Being able to accept changes in occupational activities, adapt to disease-related impairments and be flexible makes reintegration easier. People who adapt easily in a new work environment, with new colleagues and doing new tasks, can better reintegrate into a new job than people who still hope to get their own job back."

The meaning of work. VRP found that having positive ideas about the role of work can influence the reintegration process. Work can help achieve results, improve personal identity and boost self-esteem. Sick-listed clients who give great significance to work reintegrate more easily than those who do not.

A 45-year old male VRP working for 20 years with long-term sick-listed blue- and white-collar employees highlighted the importance of the meaning of work in this way: "Work is far more than a job. Of course you need a job to pay your expenses, but work is above all an activity through which a person fits into society and enables one to grow, learn, and develop a sense of identity and worth. The first step of reintegration is to make sick-listed employees discover this kind of value by themselves. If the sick-listed employee is able to look at work in this way, then the reintegration will become much easier."

\section{Theme 4 - a supportive work environment}

Positive characteristics of the work environment such as type of job, size of the enterprise, distance to the workplace, good social and physical environment and the availability of financial incentives were considered promoting factors for RTW.

Workplace characteristics. Working in large companies (>50 employees) and in sectors with more work opportunities make it possible that employees can be easily placed in modified work and that more work is available for sick listed employees. A short distance to the workplace contributes to early RTW; a long distance to work is an extra barrier to surpass.

The benefits of healthy working relationships. VRP stressed the importance of positive attitudes of employers toward people with disabilities in the workplace. Having high social support from supervisors and coworkers was mentioned as an important promoting factor for RTW.

A 48-year-old female VRP with 15 years experience with low-educated employees in the production sector said: "The roles of the employer and co-workers are of great importance during the reintegration process. They have to accept the disabled worker; the way in which the employer treats the sick-listed employee can be decisive for the reintegration. There has to be a good match between them to make reintegration succeed."

\section{Providing an adequate physical work environment. The} importance of having modified work, availability of workplace accommodations, ergonomic workstations, modified work schedules, transitional duty, alternative duty and having control over work and rest periods were stressed by the participants. A 43-year-old female VRP with 15 years experience in the industry sector stressed: "Sick-listed employees depend completely on the availability of work accommodations in the workplace. The better the workplace fits the needs of the employee, the sooner he will return to work. Sometimes there are no possibilities to provide modified work, especially in small companies; the government should reserve modified workplaces for the workdisabled."

Stimulating financial measures to improve work participation. Financial measures that minimize the financial risks for employers who employ the chronic work disabled are very important to promote RTW. Financial incentives for the employee were also mentioned by the participants, such as providing financial bonuses for sick-listed employees who succeed to return to work earlier. An experienced 48-year-old VRP who works with middle-low educated sicklisted employees with chronic musculoskeletal disorders said: "Providing financial security is important because most employers are not willing to employ the work-disabled without receiving financial incentives. Bonuses for employers who hire more work-disabled employees could help overcome financial obstacles. Providing bonuses to sick-listed employees who return earlier to work could also be an important incentive, because the financial aspect plays a more important role than you can imagine." 


\section{Theme 5 - relevance of a stimulating social environment}

Social environmental factors are related to the beneficial effects of having access to good social network, motivating personal contacts and positive role models in the social environment of the employee (eg, family members, friends, and neighbours) that can influence positively and encourage the worker to resume work. Having a stable social situation was also mentioned as a promoting factor. Social contacts of the sick-listed employee should be aware of the possibilities to RTW so that they can advice or help the employee in some way. Employers and social security organizations that provide support and advice during the reintegration process were also mentioned as important promoting factors.

Tackling social problems. A 47-year-old female VRP with 18 years experience in the private sector noted: "Longterm sick-listed clients often have similar backgrounds, including complex social problems. This point should not be forgotten during the reintegration process. Sick-listed employees should, in the first place, be provided with measures to alleviate their non-medical problems, such as solutions concerning how to cope with family issues or financial problems. From that starting position, it is easier to achieve sustained RTW. Solving or reducing social problems of the sick-listed employee help achieve reintegration because it brings an inner calm that can help the employee concentrate on the reintegration. Reintegration fails often just because of unsolved social problems."

\section{Crucial components of RTW interventions used by rehabilitation counselors}

The second main question in this study was: "what are the crucial aspects of RTW interventions used by VRP to reintegrate long-term sick-listed employees?" Table 2 summarizes the key findings.

Gathering complete information and setting priorities. Gathering as complete as possible information about the client is crucial, because it provides valuable information that helps to analyze the burden of the client, set pri-

Table 2. Crucial components of return-to-work (RTW) interventions according to vocational rehabilitation professionals.

Crucial components of RTW interventions

1. Gathering complete information and setting priorities.

2. Improving qualifications.

3. Influencing cognitions.

4. Monitoring the sick-listed employee through the rehabilitation process and after RTW.

5. Offering tailor-made interventions at different stages within a personal time-bound action plan.

6. Preparing the sick-listed employee and the work environment for RTW. orities of actions, and choose an adequate intervention and workplace. An experienced 58-year old male VRP with 35 years experience in the ship industry stressed the importance of information gathering and priority setting before choosing a strategy: "A client is sitting in front of you, you explore the situation thoroughly and analyze it deeply; which obstacles impede the client to resume work? Are there other problems besides disease? If the person has serious private problems, then you should first help him to solve or alleviate these issues. Due to the great impact of these private issues on the lives of employees, it is urgent to tackle these barriers first; otherwise work rehabilitation will not succeed. Sick-listed employees facing these kinds of obstacles cannot concentrate or put enough effort into work; this means that you should set priorities and tackle different obstacles. This knowledge helps to choose your strategy, to decide which tools and methods best fit this individual and is decisive for successful reintegration."

Improving qualifications. An important aspect of interventions is to improve the suitability of the employees for different occupations. To achieve this goal, clients may have to undergo re-training or follow additional courses. The VRP should investigate suitable training options according to the needs of the client. The personal qualifications of the employee in different areas (eg, competencies, knowledge, social skills, written and oral communication skills, and assertiveness should be improved) in order to increase the chances of reintegration. Trainings for groups of sick-listed employees who face similar obstacles can also be helpful because it stimulate social interactions and social networking within the group's members.

Influencing cognitions. VRP stressed the importance of influencing cognitions, negative emotions, and negative RTW expectations by long-term sick-listed employees in order to stimulate reintegration.

A 51-year old male VRP with 15 years experience in the work reintegration of workers in the administrative sector said: "Some barriers are not as obvious as others. Many employees on long-term sick leave not only suffer from medical diseases, but also have a lack of self-confidence and feelings of fear, anxiety, and negative work expectations, which can impede reintegration. We gradually increase the self-awareness of these clients and challenge irrational thoughts. We try to make them confident that they will be able to function in a new work situation."

The participants mentioned that cognitive methods are important to influence behavior, motivation, acceptation of sickness and handicaps, self-responsibility, self-care, autonomy, RTW expectations, self-insight, self-confidence and self-efficacy. 
A 47-year old VRP with 12 years experience in work rehabilitation of blue-collar workers stressed the importance of influencing cognitions: "Many things change in the life of a sick-listed employee after two years of sick leave, such as daily activities and social roles. People get used to a life without work in which they receive sickness benefits, experience inactivity, and take care of the household and the children; the whole family gets used to this situation. Some people even believe that they have "a balanced life". Sometimes sick-listed employees are not willing to change their situation, and then it is necessary to develop a sense of responsibility and positive attitude towards work. We have to make them aware of their duties in the society and make it clear to them that they need to set a good example for their children. We also invite the partners because they can also influence the behaviour of the client. To change such attitudes, you first need to change the beliefs."

\section{Monitoring the sick-listed employee through the reha- bilitation process and after RTW. Long-term sick-listed employees often face complex situations involving psychological stress, anxiety, chronic pain and need individual assistance during the reintegration. VRP should provide clients with ongoing support throughout the rehabilitation process and, after they have been re- introduced into the workplace, using on-the-job evalu- ations and regular follow-up. This is necessary to help monitor the client's progress after RTW to prevent sick leave. Clear communication with the employee and providing personal attention are important aspects of the interventions. Contact persons at the workplace and VRP should be easy accessible for the person who is reintegrating.}

Offering tailormade interventions at different stages within a personal time-bound action plan. Long-term sick-listed employees are individuals with different backgrounds, problems, and needs. Therefore, they need specific interventions according to their specific cases. Multidisciplinary teams should work synchronically to solve the problems that impede successful RTW. The participants highlighted the importance of early intervention and a time-scheduled personal plan of action with clear, achievable goals. Due to the multifactorial nature of long-term sick leave, different strategies (interventions) at different stages of the sick leave path may be needed to promote RTW. The specific situation of the individual at a specific moment in time should be leading for a right choice of the RTW intervention. Both the sick-listed employee and the VRP should create together this plan of action and work together towards reintegration at an appropriate stage.

A 45-year old female VRP with 12 years experience in work rehabilitation of industry workers on long-term sick leave explained: "The objective is that the person stands up from his chair in order to regain structure in his life and re-activate gradually. The life of a person on long-term sick leave has become passive. We make a personal time-bound plan-of-action with achievable goals; it is important that every successful little step the person achieves motivates one to set a next step. Sometimes we arrange voluntary work or a stage to mobilize people, regain self-confidence, and make them feel valuable. Every client has a different background, character, medical situation and has, therefore, different needs. It is imperative to choose the right method, to select the right professional and the right time for intervention."

Preparing the sick-listed employee and the work environment for RTW. VRP stressed the importance of preparing the workplace (work accommodations and coaching of supervisors and colleagues) and the sick-listed employee for the reintegration. Sick-listed employees should visit the new workplace in advance and be aware of the work situation before they start reintegration. Employers and co-workers should be informed about how to cope with the handicap of the sick-listed employee and should be involved in the reintegration process of the colleague. VRP should have frequent contact with the employee during reintegration, monitor and anticipate problems at work, and help the employee through the transition process.

A 47-year old female VRP working for 16 years with blue-collar sick-listed employees explained: "Many supervisors and colleagues don't know how to handle reintegrated sick-listed employees. Sometimes they don't know how to work together with a colleague who is missing one arm, who suffers physical impairments, mental disorders or is a cancer survivor. We inform (with permission of the employee) those present in the workplace environment about the problems of the sick-listed employee, and the best ways to cope with the disabilities of the sick-listed employee. Most employers and co-workers appreciate this information. The supervisor plays a crucial role; he has to give a good example and arrange work accommodations."

\section{Relationship between RTW interventions and influ- enceable promoting factors for RTW}

Further analysis of the data shows that the promoting factors for RTW have common aspects with the crucial aspects of the RTW-interventions mentioned by the VRP. Some RTW-interventions can be linked to more than one promoting factor. Table 3 shows the links between the crucial aspects of RTW-interventions and the influenceable promoting factors for RTW. 


\section{Discussion}

\section{Summary of main findings}

In the opinion of experienced VRP, the following factors can stimulate sustained RTW of long-term sick-listed employees: (i) employee-based vocational guidance; (ii) integral and effective communication and collaboration with the employee and other RTW stakeholders; (iii) positive personal characteristics of the sick-listed employee; (iv) a supportive work environment; and (v) a stimulating social environment.

VRP find that crucial aspects of RTW interventions are: (i) gathering complete information and setting priorities; (ii) improving qualifications; (iii) influencing cognitions; (iv) monitoring the sick-listed employee during the rehabilitation process; (v) offering tailormade interventions at different stages within a personal time-bound action plan; and (vi) preparing the employee and the work environment for RTW. The data analysis showed that there is a link between RTW interventions and the promoting factors. Some crucial aspects of interventions (eg, monitoring the sick-listed employee, offering interventions, and preparing the employee for RTW) have common points with more than one promoting factors (table 3 ).

\section{Methodological considerations}

To our knowledge, there are no qualitative studies concerning influenceable promoting factors for sustained RTW and interventions targeted at long-term $(>1.5$ years) sick-listed employees. Most studies have focused on factors and interventions for employees who are on sick leave for $<6$ weeks, and crucial information about promoting factors of specific chronic diseases and interventions used in this group of clients is still lacking $(11,12)$. This study focuses on potentially influenceable factors that stimulate the RTW process. Early studies show that a number of variables that are amenable to change such as beliefs and recovery expectations (13, 14), motivation (15), and self-esteem (16) of the sicklisted employee are useful in predicting work outcomes for these workers.

In this study, we use the definition "sustained RTW", which is a standard used by the Dutch Workers Insurance Authority for the registration of RTW outcomes of sick-listed employees. According to this definition, sustained RTW means work resumption that lasts $\geq 6$ months. We asked the respondents to think about clients who were off work and what they would do to help them initiate a return to the workplace and sustain it once a re-entry was made. Our respondents mentioned that sustained RTW was their goal and that they followed the clients for 6 months after re-entry into the workplace.
Table 3. Relation between return-to-work (RTW) interventions and influenceable promoting factors for RTW.

\begin{tabular}{ll}
\hline RTW intervention & Promoting factor \\
\hline $\begin{array}{l}\text { Gathering complete informa- } \\
\text { tion and setting priorities }\end{array}$ & Employee-based vocational guidance \\
Improving qualifications & Employee-based vocational guidance \\
Influencing cognitions & $\begin{array}{l}\text { The sick-listed employee as promoting } \\
\text { factor }\end{array}$ \\
& A stimulating social environment \\
& A supportive work environment \\
Monitoring the sick-listed & Integral and effective communication \\
employee through the & between the sick-listed employee and all \\
rehabilitation process and & RTW-stakeholders \\
after RTW & A supportive work environment \\
$\begin{array}{l}\text { Offering tailormade } \\
\text { interventions at different } \\
\text { stages within a personal } \\
\text { time-bound action plan }\end{array}$ & $\begin{array}{l}\text { Integral and effective communication } \\
\text { between sick-listed employee and all }\end{array}$ \\
& RTW stakeholders \\
Preparing the sick-listed & A supportive work environment \\
employee and the work & Integral and effective communication \\
environment for RTW & between the sick-listed employee and all \\
& RTW-stakeholders \\
& A supportive work environment \\
& A stimulating social environment \\
\hline
\end{tabular}

The inductive method that we used in this qualitative study allowed us to explore emerging topics from the perspective of professionals specialized in work rehabilitation of employees on long-term sick leave, and this enabled us to gain valuable insights into the VRP perspective on RTW. VRP are the RTW stakeholders who have the closest contact with long-term sick-listed employees, in contrast to other health professionals, who (often) see the client briefly; these VRP, therefore, are useful sources of information pertaining to factors that promote RTW.

This study represents the views of VRP working in the Netherlands. Our participants have many years experience in the work reintegration of employees on sick leave and are experts in this field. To minimize the risk for socially desirable answers, we used a semi-structured, open-ended interview guide carefully elaborated to elicit the opinions of the participants. The interviewer used direct, clear questions and specific interview techniques. All the questions were worded as clearly and concisely as possible to avoid ambiguity. This uniformity of questions ensured that each participant responded with the same response set. The recruitment of participants continued until data saturation was reached.

The interviewer was an insurance physician with extensive experience in interviewing employees on long-term sick leave and with specific knowledge on factors related to sick leave. Insurance physicians are medical professionals specialized in the assessment of the work ability of employees on sick leave and have specific knowledge of this field. 
The strength of this study is that we explored the breadth of perspectives among our participants, who were selected by purposive sampling to provide as wide a range of experiences as possible. We interviewed a sufficient number of respondents to achieve data saturation. Our sample included VRP specialized in the placement of all types employees from different working sectors, company sizes, educational levels, and different physical and/or mental diseases. For this reason, our findings may capture the perspectives of most types of rehabilitation VRP in the Netherlands.

\section{Interpreting our findings}

Several findings of the present study are credible in light of previous research. For instance, our participants expressed that effective communication with the client is the cornerstone of successful work rehabilitation. This is in accordance with the assumption that a close interpersonal client-VRP relationship is the key context for vocational rehabilitation interventions (17). Early studies have also shown that effective communication can improve adherence to treatment and disease outcomes $(18,19)$. Communication with the client in the same language was also mentioned by the participants as a promoting factor. This is in concordance with the finding that language and culture-concordance enhances the doctor-patient relationship (20) and that communication problems can obstruct the rehabilitation process (21). According to the VRP, all actors and actions involved in the RTW-process should be centered on and involve the long-term sick-listed employee. Previous studies have also shown the importance of patient centeredness (22, 23 ) and shared decision-making (24). Other studies have also shown that individualized attention and good relationships with the employee are RTW facilitators (25).

Our participants stressed the importance of considering the individual in his/her own context (ie, special consideration should be given to the overall situation of the client and not just to his/her medical problems). This is in accordance with the holistic perspective of the International Classification of Functioning, Disability and Health (ICF), in which the individual and his context are taken into account (6).

The results of this study show that non-medical factors play an important role in long-term sick leave and reaffirm the complexity of the RTW-process. This is in line with findings from the literature that show that longterm sick leave is the result of an interaction of factors acting within the context of the sick-listed employee (6-7, 26-28). A secondary finding is that RTW interventions should simultaneously target obstacles at different levels in order to enhance work rehabilitation of longterm sick-listed employees. VRP stressed the importance of multidisciplinary teams working towards a common goal, because long-term sick-listed employees often have complex problems that need different specialists. Previous studies also indicate that multidisciplinary programs are more effective in reducing work disability than monodisciplinary programs $(29-34)$ and have beneficial health effects for employees with chronic disabilities (35).

This study shows, in accordance with previous studies, that personal characteristics of the employee, such as having a positive attitude towards going back to work, and social support in the workplace $(36,37)$ are promoting factors for RTW. Our findings are in line with a recent study that showed that positive working conditions, supportive workplace relationships, and work satisfaction are RTW facilitators following occupational injury (38). A systematic review found evidence supporting benefits of RTW interventions including work rehabilitation professionals with shorter disability duration and lower costs (8). The role of our participants is similar to the role of other VRP in other countries such as Sweden, Finland, Norway, USA, Canada, and Australia (39). These professionals coordinate the different aspects of the RTW process, facilitate and support sustained RTW, provide assistance to the sick-listed employee during the RTW process, and communicate with all different RTW actors.

The data analysis showed there is a relation between RTW interventions and promoting factors for RTW. These findings are in line with the concept that individuals function within a context in which several factors play a role.

Many promoting factors mentioned by our participants were also described in earlier studies on the perspectives of other RTW stakeholders. Healthcare providers stressed the importance of effective communication (19) and patient centeredness (18). Studies with patients and employment service providers showed that individualized attention to the patient $(22,23)$ and good relationships with the client (24) promote RTW. Employment counselors pointed out the importance of a close interpersonal client-VRP relationship in the RTW process (18). Social insurance officers mentioned that the employer's attitude to the employee is an essential factor for successful vocational rehabilitation (40). Employees on sick leave mentioned that taking the client seriously promotes RTW (7). A previous study on the views of a wide group of stakeholders (managers, workers, occupational health professionals, VRP, etc) stressed the importance of good communication, trust and credibility among RTW stakeholders (27).

RTW is a complex matter and different stakeholders are involved in the process. The results of this study represent the views of a particular group of RTW stakeholders, namely, VRP working in the Netherlands. The literature suggests that the views of stakeholders on possible solutions to address problems 
can be influenced by their values and perspectives on the underlying causes of the problem (41). In general, all RTW stakeholders have the common goal of successful work resumption of employees on sick leave. However, it is important to take into account that RTW stakeholders operate in different contexts and may have competing objectives and different motivations (42). It could be argued that our participants could also have specific interests in the findings of this study or that they would have tried to give a better impression of their achievements. However, VRP not only mentioned their successes but also their failures in the reintegration of sick-listed employees. Furthermore, the opinions of our participants are completely anonymous and cannot be linked to specific individuals or the reintegration services where these professionals work. Our data are consistent with other studies that found that commitment of stakeholders should be stimulated to achieve successful RTW $(43,44)$. According to the findings in this study, our participants are important external RTW stakeholders who act as motivators for employees on long-term sick leave. VRP provide support to the employer in the management of sick leave and play an important role in supporting RTW strategies and recommending work accommodations, work restrictions, and workplace advice.

The results of this study provide valuable information about influenceable promoting factors for sustained RTW by employees on sick leave for $>1.5$ years. The added value of scientific knowledge about influenceable factors for RTW is the fact that they are potentially amenable to change with the use of interventions.

Another important conclusion of this study is that RTW interventions should focus on different factors (eg, ones that are personal, medical and work-related) and should differ in emphasis and content depending on the time since the start of sick leave and the individual psychological characteristics of the employee (ie, tailormade interventions). Special attention should be given to a multidisciplinary, coordinated approach between all RTW actors (eg, clinicians, occupational and insurance physicians, rehabilitation experts, and supervisors).

\section{Implications for future research}

This qualitative study represents the views of Dutch VRP. According to its results, influenceable promoting factors can be important in achieving sustained RTW of long-term sick-listed employees. Further research, using a different methodology would be needed to confirm these findings. It would be interesting to compare the present findings with the views of VRP in other countries. In the opinion of our participants, there are several potentially influenceable promoting factors, such as the work environment, the cognitions of the employee, the quality of guidance the communication between the sicklisted employee and other RTW stakeholders that can be useful to improve the RTW of long-term sicklisted employees. These new insights can aid healthcare professionals in obtaining a better understanding of the occupational rehabilitation process and providing better advice regarding RTW. The factors identified in this study may provide a useful framework for healthcare professionals to communicate with long-term sicklisted clients and explore the factors associated with RTW. This framework of factors may help health care professionals to identify behavioral, social, personal, and environmental promoting factors and stimulate them to improve work resumption. This implies that physicians should recognize the factors that encourage RTW and stimulate these factors among long-term sick-listed employees. Knowledge about potentially influenceable promoting factors and crucial aspects of interventions can help health professionals develop interventions that promote RTW.

\section{Concluding remarks}

According to experienced VRP, influenceable workrelated and personal factors (such as work environment, cognitions, and work motivation) are decisive for an employee's RTW success In the opinion of VRP, the use of combined interventions in a holistic approach involving the worker and his/her environment is the best way to address the multicausality of work disability and could help maximize RTW outcomes.

The results of this study have important implications for improving the work rehabilitation of clients on long-term sick leave. Healthcare professionals should be trained to identify aspects that might enable the RTW of a particular employee and tackle the barriers that impede work reintegration. Interventions should simultaneously target the multiple problems of sick-listed employees instead of only the medical issues.

Reintegration of long-term sick-listed clients is obviously a difficult task. It should be recognized that, due to the complexity of the problem, healthcare professionals alone cannot tackle the multiple obstacles for an employee's return to the workplace. Improvement of RTW outcomes requires the concerted efforts of clients and their families, healthcare professionals, healthcare authorities, employers, and insurers.

\section{References}

1. Henderson M. Long-term sickness absence. BMJ 2005;330:802-803. doi:10.1136/bmj.330.7495.802.

Scand J Work Environ Health 2011, vol 37, no 6 
2. Vestling M, Tufvesson B, Iwarsson S. Indicators for return to work after stroke and the importance of work for subjective well-being and life satisfaction. J Rehabil Med 2003;35:127131. doi:10.1080/16501970310010475.

3. Bernacki EJ, Guidera A, Jill RN, Schaefer, JA, Tsai S. A Facilitated Early Return to Work Program at a Large Urban Medical Center. Journal of Occup and Environ Med 2000;42:1172-1177. doi:10.1097/00043764-20001200000010 .

4. Hagen E, Grasdal A, Eriksen HR. Does early intervention with a light mobilization program reduce long-term sick leave for low back pain: A 3-year follow-up study. Spine 2003; 28:23092316. doi:10.1097/01.BRS.0000085817.33211.3F.

5. Hagen KB, Thune O. Work Incapacity from Low Back Pain in the General Population Spine 1998;23:2091-2095

6. World Health Organization. International Classification of Functioning, Disability and Health (ICF). Geneva; World Health Organisation 2001.

7. Dekkers-Sánchez PM, Wind H, Sluiter JK, Frings-Dresen, $\mathrm{MH}$. A qualitative study of perpetuating factors for long term sick leave and promoting factors for return to work: chronic work disabled patients in their own words. J Rehabil Med 2010;42:544-552. doi:10.2340/16501977-0544

8. Franche RL, Cullen K, Clarke J, Irvin E, Sinclair S, Frank J. Workplace- based return-to-work interventions: a systematic review of the quantitative literature. J Occup Rehabil 2005;15:607-31 doi:10.1007/s10926-005-8038-8.

9. Pope C, Mays N. Qualitative research in health care. Third edition. 2006. Blackwell publishing Ltd; 2006, p.69-73.

10. Patton, M. Q. (2002). Qualitative evaluation and research methods (3rd ed.). Thousand Oaks, CA: Sage Publications.

11. Slebus FG, Kuijer PP, Willems HJ, Sluiter JK, FringsDresen MH. Prognostic factors for work ability in sick listed employees with chronic diseases. Occup Environ Med 2007;64:814-819. doi:10.1136/oem.2006.031807.

12. Dekkers-Sánchez PM, Hoving JL, Sluiter JK, Frings-Dresen $\mathrm{MH}$. Factors associated with long term sick leave in sick listed employees: a systematic review. Occup Environ Med 2008;65:153-157.doi:10.1136/oem.2007.034983.

13. Iles RA, Davidson M, Taylor NF, O'Halloran P. Systematic review of the ability of recovery expectations to predict outcomes in non-chronic non-specific low back pain, J Occup Rehabil 2009;19:25-40. doi:10.1007/s10926-008-9161-0.

14. Heymans MW, de Vet HC, Knol DL, et al. Workers' beliefs and expectations affect return to work over 12 months. J Occup Rehabil 2006;16:685-695. doi:10.1007/s10926-006-9058-8.

15. Berglind $\mathrm{H}$, Gerner U. Motivation and return-to-work among the long-term sick-listed: An action theory perspective. Disability \& Rehabilitation 2002;24:719-726. doi:10.1080/09638280210124301

16. Chapin MH, Kewman DG. Factors affecting employment following spinal cord injury: A qualitative study. Rehabilitation Psychology 2001;46:400-416. doi:10.1037/00905550.46 .4 .400

17. Grahan MD. Addiction, the addict and career: Considerations for the employment counselor. Journal of employment counseling 2006;43:168-178.

18. Stewart M, Brown J, Donner A, McWhinney IR, Oates J, Weston $\mathrm{W}$ et al. The Impact of Patient-Centered Care on Outcomes. J Fam Pract 2000;49:796-804.

19. Beck RS, Daughtridge R, Sloane PD. Physician-Patient Communication in the Primary Care Office: A Systematic Review. J Am Board Fam Pract 2002;15:25-38.

20. Ferguson WJ, Candib LM. Culture, Language, and the DoctorPatient Relationship. Fam Med 2002;3:353-361.

21. Sloots M, Dekker JH, Pont M, Bartels EA, Geertzen JH, Dekker J. Reasons of drop-out from rehabilitation in patients of Turkish and Moroccan origin with chronic low back pain in The Netherlands: A qualitative study. J Rehabil Med 2010;42:566-573. doi:10.2340/16501977-0536.

22. Berwick, DM. My right knee. Annals of Internal Medicine 2005;142:121-125.

23. Little P, Everitt H. Observational study of effect of patient centredness and positive approach on outcomes of general practice consultations. BMJ 2001;323:908-911. doi:10.1136/ bmj.323.7318.908.

24. van Til J, Drossaert CH, Punter A, Ijzerman MJ. The potential for shared decision-making and decision aids in rehabilitation medicine. J Rehabil Med 2010;42:598-604. doi:10.2340/16501977-0549.

25. Henry AD, Lucca AM. Facilitators and barriers to employment: The perspectives of people with psychiatric disabilities and employment service providers. Work 2004;22:169-182.

26. Schultz I, Stowell A, Feuerstein M, Gatchel R. Models of Return-to work for musculoskeletal disorders. J Occup Rehabil 2007;17:327-352. doi:10.1007/s10926-007-9071-6.

27. Friesen MN, Yassi A, Cooper J. Return-to-work: the importance of human interactions and organizational structures. Work 2001;17:11-22.

28. Krause N, Dasinger LK, Deegan LJ, Rudolph L, Brand RJ. Psychosocial job factors and return-to-work after compensated low back injury: A disability phase-specific analysis. Am J Ind Med 2001;40:374-92. doi:10.1002/ajim.1112.

29. Sullivan M, Feurstein M, Gatchel R, Linton S, Pransky G. Integrating Psychosocial and Behavioral Interventions to achieve optimal rehabilitation outcomes. J Occup Rehabil 2005;15:475-489. doi:10.1007/s10926-005-8029-9.

30. Guzman J, Esmail R, Karjalainen K. Multidisciplinary biopsychosocial rehabilitation for chronic low-back pain. The Cochrane database of Systematic Reviews: The Cochrane Library, 2004.

31. Blackwell TL, Leierer SJ, Haupt SS, Kampitsis A, Wolfson JR. Prediction of Vocational Outcomes for Workers' Compensation Claimants with Back Injury. J Appl Rehabil Counsel 2004;35:32-38.

32. Schonstein E, Kenny D, Keating J, Koes B. Work conditioning, work hardening and functional restoration for workers with back and neck pain. Cochrane Database Syst Rev 2003; CD001822.

33. Sullivan MJ, Adams H, Rhodenizer T, Stanish WD. A 
psychosocial risk factor-targeted intervention for the prevention of chronic pain and disability following whiplash injury. Phys Ther 2006;86:8-18.

34. Suoyrjö H, Oksanen T, Hinkka K, Kivimäki M, Klaukka $\mathrm{T}$, Pentti $\mathrm{J}$ et al. The effectiveness of vocationally oriented multidisciplinary intervention on sickness absence and early retirement among employees at risk: an observational study. Occup Environ Med. 2009; 66:235-242.

35. Larsson Lund M, Lexel J. A positive turning point in life - how persons with late effects of polio experience the influence of an interdisciplinary rehabilitation programme. J Rehabil Med 2010;42:559-565. doi:10.2340/16501977-0559.

36. Puolakka K, Ylinen J, Neva M, Kautiainen H, Häkkinen A Risk factors for back pain-related loss of working time after surgery for lumbar disc herniation: a 5-year follow-up study. Eur Spine J 2008;17:386-392. doi:10.1007/s00586-0070552-2.

37. Lindström B, Röding J, Sundelin G. Positive attitudes and preserved high level of motor performance are important factors for return to work in younger persons after stroke: A national survey. J Rehabil Med 2009;41:714-718. doi:10.2340/16501977-0423.

38. Young AE. Return to work following disabling occupational injury - facilitators of employment continuation. Scand J Work Environ Health 2010;36(6):473-483. doi:10.5271/ sjweh.2986.

39. Shaw W, Hong Q, Pransky G, Loisel P. A Literature review describing the role of Return-to-Work Coordinators in
Trial Programs and Interventions designed to prevent Workplace Disability. J Occup Rehabil 2008;18:2-15. doi:10.1007/s10926-007-9115-y.

40. Ahlgren A, Bergroth A, Ekholm J, Ekholm KS. Selection of clients for vocational rehabilitation at six local social insurance offices: a combined register and questionnaire study on rehabilitation measures and attitudes among social insurer offices. J Rehabil Med 2008;40:178-184. doi:10.2340/16501977-0157

41. Guba, E. G., \& Lincoln, Y. S. (1989). Fourth generation evaluation. Newbury Park, CA: Sage.

42. Young AE, Wasiak R, Roessler RT, McPherson KM, Anema JR, van Poppel MN. Return- to-work outcomes following work disability: stakeholder motivations, interests and concerns. J Occup Rehabil. 2005;15(4):543-56. doi:10.1007/s10926-005-8033-0.

43. Lotters F, Meerding WJ, Burdorf A. Reduced productivity after sickness absence due to musculoskeletal disorders and its relation to health outcomes. Scand J Work Environ Health. 2005;31(5):367-74.

44. Karrholm J, Ekholm K, Ekholm J, Bergroth A, Ekholm KS Systematic co-operation between employer, occupational health service and social insurance office: a 6-year followup of vocational rehabilitation for people on sick leave including economic benefits. J Rehabil Med 2008;40:628-636. doi:10.2340/16501977-0233

Received for publication: 30 October 2010 